\title{
Electron Microscopic Studies of Anodic Oxide Films on the AZ91HP Alloy
}

\author{
D. Peixoto Barbosa ${ }^{\mathrm{a}}$, G. Knörnschild ${ }^{\mathrm{a}}$, H.P. Strunk ${ }^{\mathrm{b}}$ \\ ${ }^{a}$ Federal University of Rio Grande do Sul - UFRGS, Department of Metallurgy \\ Av. Oswaldo Aranha 99, 90035-190 Porto Alegre - RS, Brazil \\ ${ }^{\mathrm{b}}$ University of Erlangen-Nürnberg, Germany Institute of Microcharacterization \\ and Central Facility for High-Resolution Electron Microscopy
}

Received: July 10, 2002; Revised: November 5, 2002

\begin{abstract}
A Mg-9wt.Al-1wt.\%Zn-alloy was anodized up to $90 \mathrm{~V}$ with constant current/constant voltage in an electrolyte which contained the compounds of the HAE-process $\left(\mathrm{KOH}, \mathrm{Al}(\mathrm{OH})_{3}, \mathrm{KF}, \mathrm{Na}_{3} \mathrm{PO}_{4}\right.$ and $\mathrm{KMnO}_{4}$ ). Electron microscopic examinations revealed a highly porous and irregular film structure. The distribution of the elements in the film was measured with energy dispersive spectrometry on specimens prepared in cross section for the transmission electron microscope. The main characteristic found was a fluoride-enriched zone of about $100 \mathrm{~nm}$ thickness at the metal / film interface. Practically no manganese from the permanganate was detected in this fluoride-enriched zone.
\end{abstract}

\section{Keywords: magnesium, anodizing}

\section{Introduction}

Magnesium alloys are very interesting materials for light weight constructions. Compared with other light metals, they have substantial technical and economic advantages due to their low density $\left(\mathrm{Mg}: 1,74 \mathrm{~g} / \mathrm{cm}^{3}, \mathrm{Al}: 2,7 \mathrm{~g} / \mathrm{cm}^{3}\right.$, Ti: $\left.4,5 \mathrm{~g} / \mathrm{cm}^{3}\right)$, the longer lifetime of metallic molds and cutting tools and the possibility of higher production rates ${ }^{1,2}$.

Their poor corrosion resistance, however, makes the application of protective layers, for example by anodizing, indispensable.

Anodic oxidation is a technique used since long time for the corrosion protection of magnesium alloys. Anodic films on magnesium, however, never reached the good corrosion resistance of anodic films on aluminum. Whereas the anodization of aluminum is possible in a great number of neutral electrolytes or of di- or trivalent acids, the anodization of magnesium requires more complex recipes, using a mixture of various inorganic salts, as in the case of the HAE- or the DOW 17-process ${ }^{1,3}$. The function of each one of these constituents in the process is frequently not clear. The HAE-process is still interesting, since it is a chromate-free process $^{4}$, however, chromate is frequently used for sealing. As in the case of aluminum anodizing the elimination of process steps that involve $\mathrm{Cr}(+\mathrm{VI})$ ions is a present aim in magnesium anodizing.

Breakdown of anodic films on magnesium alloys occurs already at low voltages 5 . As a consequence of these breakdown events, so-called sparks or micro-arcs are formed on the surface ${ }^{6}$. The locally high current density passing through these defects causes localized evaporation of the electrolyte, and the high electric field leads to the ionization of the vapor. In this way, a significant number of ionized species can be formed on the surface and participate in the film forming process. Therefore, the anodization of magnesium is not a well understood process.

Some new promising processes appeared in the last years, which seem to better control these plasmaelectrochemical effects ${ }^{7,8}$. In the case of aluminum anodizing, films containing the hard $\alpha-\mathrm{Al}_{2} \mathrm{O}_{3}$-phase could be produced $^{9-11}$, in the case of magnesium anodizing, the films seem to have an improved corrosion resistance ${ }^{1,2}$.

In the present work, specimens of a Mg-9wt.Al-1wt.\%Zn-alloy were anodized in an electrolyte which contained the compounds of the HAE-process. Depth profiles of the elements incorporated from the electrolyte 
were determined by energy dispersive X-ray spectrometry (EDS) in the transmission electron microscope.

\section{Experimental}

Anodizing was performed with an AZ91HP alloy of the composition shown in Table 1 . The specimens were prepared by grinding the surface to a 2400 grit finish and polishing with $1 \mu \mathrm{m}$ diamond paste. The specimens were then cleaned with destilled water in an ultrasonic bath and dried with air. The electrolyte had a composition as used in the HAE process, i.e. consisted of $165 \mathrm{~g} / \mathrm{l} \mathrm{KOH}, 34 \mathrm{~g} / \mathrm{l} \mathrm{Al}(\mathrm{OH})_{3}$, $34 \mathrm{~g} / \mathrm{l} \mathrm{KF}, 34 \mathrm{~g} / \mathrm{l} \mathrm{Na} \mathrm{PO}_{4}$ and $20 \mathrm{~g} / \mathrm{l} \mathrm{KMnO}$. The tests were performed with a power source with selectable current and potential limits. Anodic films were formed in tests, which had a duration of $10 \mathrm{~min}$. During the first part of the test, the power source worked at its programmed current limit, until the voltage drop across the growing oxide film reached the chosen voltage limit, then the power source remained at this voltage and the current diminished with the further growing film. The voltage used in these tests was $70 \mathrm{~V}$ and $90 \mathrm{~V}$. The applied current density varied between 20 and $500 \mathrm{~mA} / \mathrm{cm}^{2}$.

In order to prepare oxide films in cross section for transmission electron microscopy two specimens were glued together on their filmed sides to form a sandwich. The sandwich was then mechanical thinned to about $35 \mu \mathrm{m}$ thickness and subsequently perforated by ion milling. In order to stabilize the thin specimen, a nickel ring of $10 \mu \mathrm{m}$ thickness was fixed with epoxy resin. The specimens were analyzed with a $300 \mathrm{kV}$ Philips CM 30 T/STEM Analytical Electron Microscope. EDS-line-scans of the film were measured in STEM-mode (Scanning Transmission Electron Microscopy).

\section{Results and discussion}

\subsection{Transients}

Figure1 shows a typical current transient, observed during anodizing of the magnesium alloy in the HAE-electrolyte. Sparking occurs constantly during the first phase of the test (i.e., during the phase of constant current, the first $80 \mathrm{~s}$ in Fig. 1), i.e. until the voltage limit is reached. It is a sporadic process during the second phase of the test, when the current density diminishes during further oxide growth at constant voltage. Sparking can then be observed in the form of current peaks superimposed to the current decay. It has been shown that the frequency of these events can vary significantly with the kind of electrolyte and that there exists a direct correlation between these sparking events and the structure, especially the porosity, of the films ${ }^{12}$.

\subsection{Morphology}

Studies of the anodic films in the scanning electron microscope revealed a highly porous structure. In Fig. 2a, two layers can be distinguished. The outer layer, which represents the lighter area of Fig. 2a has very large pores. The inner layer, which appears darker in Fig. 2a is denser and has smaller pores. The two layers are separated by a highly porous zone, which appears in the cross section in the transmission electron microscope in the form of elongated voids (Fig. 3). The outer layer, obviously of poor adherence, is not uniformly distributed over the surface (Fig. 2b). Larger pores are probably related with heavier sparking at these sites. EDS-analysis in the scanning electron microscope of regions with larger pores revealed a slightly higher concentration of $\mathrm{Mn}, \mathrm{K}, \mathrm{O}$ and $\mathrm{Al}$ than in the regions with smaller pores.

The porosity of the films has also been calculated from the electric charge passing through the specimen during the test. The theoretical thickness of the films was calculated by Faraday's law, using that charge, and the density of MgO. The porosity was then obtained by comparing this value with the film thickness measured in the microscope, using the formula:

$$
\mathrm{P}=\left(1-\mathrm{d}_{\mathrm{F}} / \mathrm{d}_{\mathrm{M}}\right) \times 100 \%
$$

where:

$\mathrm{P}=$ porosity in \%;

$\mathrm{d}_{\mathrm{F}}=$ film thickness calculated from Faraday's law;

$\mathrm{d}_{\mathrm{M}}=$ film thickness determined from the micrographs.

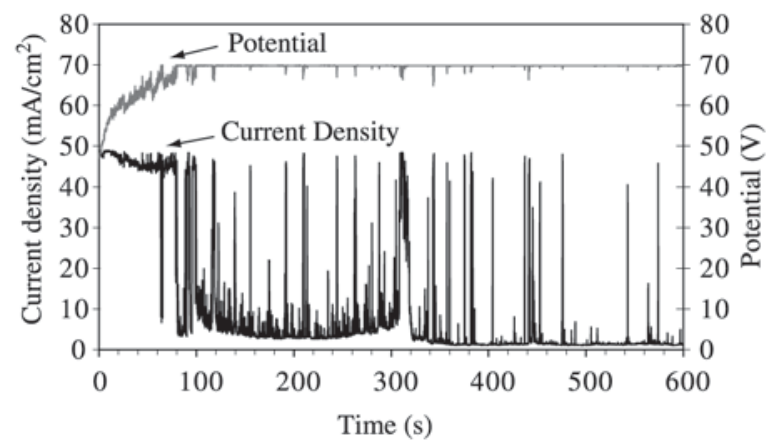

Figure 1. Current density and potential transients during anodization of the AZ91HP alloy in HAE-electrolyte.

Table 1.

\begin{tabular}{lccccccccc}
\hline Element & $\mathrm{Al}$ & $\mathrm{Zn}$ & $\mathrm{Mn}$ & $\mathrm{Fe}$ & $\mathrm{Si}$ & $\mathrm{Cu}$ & $\mathrm{Be}$ & $\mathrm{Ni}$ & $\mathrm{Mg}$ \\
\hline wt. $\%$ & $8.0-9.5$ & $0.3-1.0$ & $0.10-0.040$ & $<0.006$ & $<0.06$ & $<0.015$ & $<0.002$ & $<0.001$ & rest \\
\hline
\end{tabular}



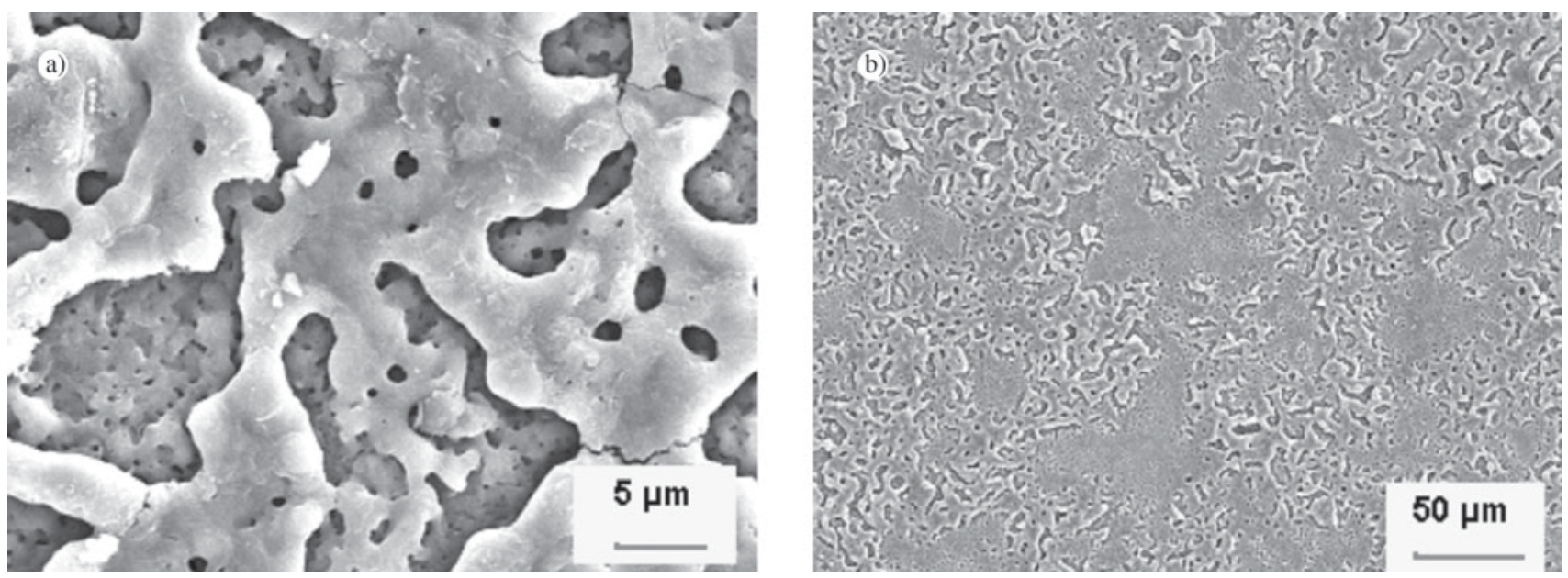

Figure 2. Scanning electron micrograph of anodic film formed at $90 \mathrm{~V}$ on AZ91HP.

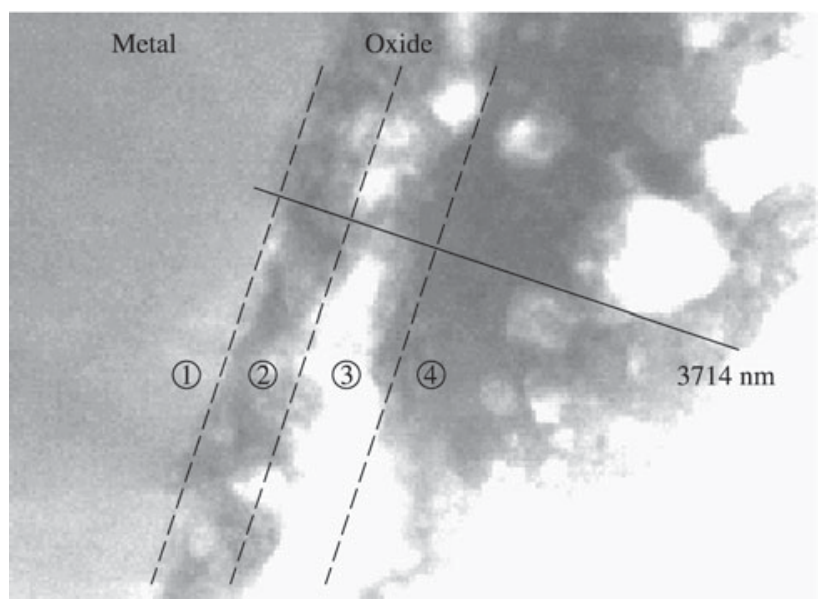

Figure 3. Transmission electron micrograph of anodic film formed at $90 \mathrm{~V}$ on AZ91HP in HAE-electrolyte. Photo in STEM-mode. The line on the photo shows the way of the line-scan in Fig. 4. (1): $\mathrm{Mg}$ alloy; (2): inner dense layer containing F- and P-enriched zone; (3): highly porous zone separating inner and outer layer; (4): outer porous layer with large pores.

A porosity up to $52 \%$ was calculated in this way. Although this calculated value seems to agree well with the visual impression one gets from the micrographs, it has to be considered only as an estimation, due to possible errors, such as the true density of the film forming phase that can differ significantly from that of $\mathrm{MgO}$. Moreover, one has to regard the efficiency of film formation, which can be reduced by concurrent reactions such as anodic oxygen evolution and by chemical dissolution of the film into the electrolyte. Gas bubbles have always been observed on the electrode surface at the beginning of the tests, which points to oxygen evolution. Film dissolution during the tests, how- ever, seems to be negligible, since it has been observed, that the charge, necessary to reach the voltage limit, did not depend on the applied current density, i.e. it did not depend on the time for film formation.

\subsection{Film composition}

The most striking property of the films, with respect to the chemical composition, is a fluoride enriched zone of about $100 \mathrm{~nm}$ at the alloy/oxide interface with a maximum fluoride concentration between 10 and $20 \mathrm{wt} . \%$. The concentration then falls rapidly to about $2 \mathrm{wt} . \%$ in the rest of the film. The concentration profile of phosphorus has also a maximum of 4-6 wt. \% near the alloy/oxide interface. The phosphorus concentration diminishes to about $2 \mathrm{wt} . \%$ towards the outer side of the film. Manganese shows also a higher concentration in the inner part of the film. However, practically no manganese was detected near the alloy/oxide interface where the film is enriched with fluoride.

The composition near the metal/oxide interface is of special interest, since it has been assumed, that the beneficial effect of ions like chromate, molibdate, permanganate etc., is to precipitate in the form of a low conductive phase. This would favor the healing of defects in the film by blocking the cathodic reaction at these $\operatorname{sites}^{13}$. In order to act in this way, these ions should be present at the metal/oxide interface, rather than in the outer part of the film ${ }^{14}$. According to this model, permanganate, which is absent near the metal/oxide interface, is not expected to have a significant effect on the corrosion resistance of the anodic oxide film on the AZ91HP alloy. Indeed, literature data confirm, that films, formed in electrolytes with a low $\mathrm{KMnO}_{4}$ concentration does not have a poorer corrosion resistance ${ }^{3}$. Fluoride, on the other hand, seems to be a substantial constituent of the film. Due to the low solubility product of $\mathrm{MgF}_{2}$, fluoride could have a beneficial effect as inhibitor in the sense 
(a)

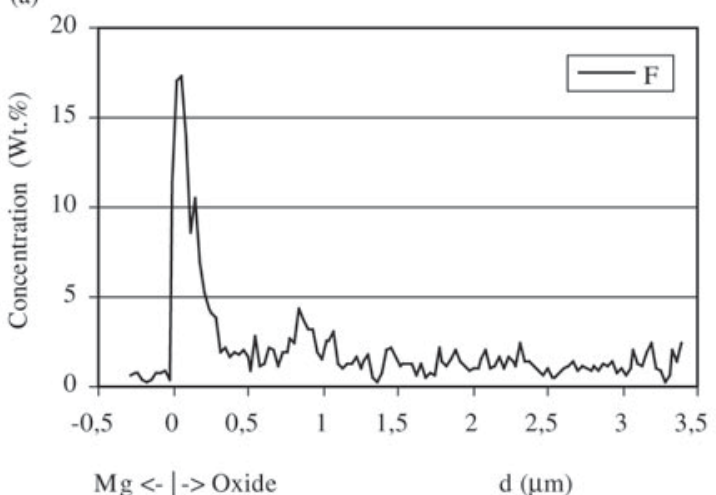

(c)

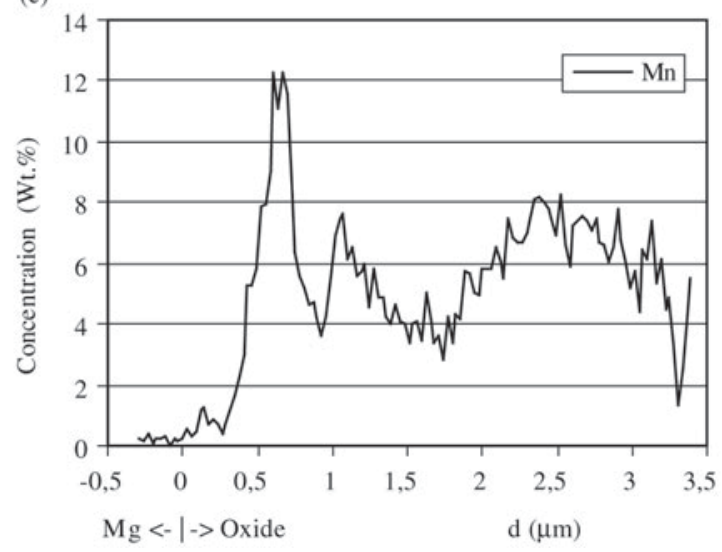

(b)

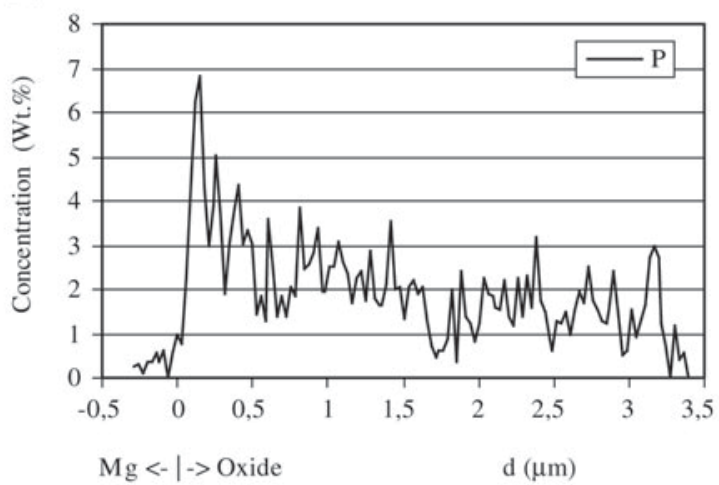

(d)

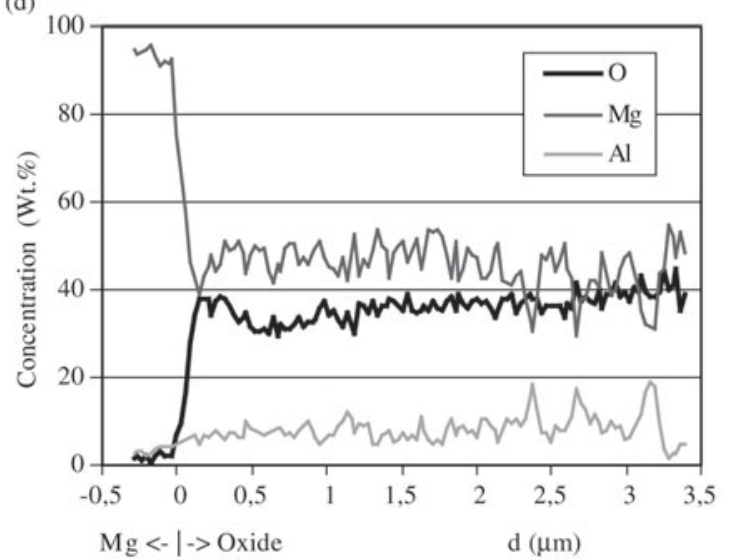

Figure 4. EDS-Line-scans over anodic oxide film shown in Fig. 3. Concentration (wt.\%) vs. distance d from the metal/oxide interface: a: Fluorine; b: Phosphorus; c: Manganese, d: Magnesium, aluminum and oxygen.

discussed above, but it could also play an important role in the film formation itself.

\section{Conclusion}

Fluorine and phosphorus are the two elements from the HAE-electrolyte, that prevail at the metal/oxide interface. These elements play probably a more direct role in film formation and in corrosion inhibition than manganese, which does not appear at the metal/film interface. In the case of manganese, this agrees with the information, that films grown in a HAE-electrolyte of low $\mathrm{KMnO}_{4}$-concentration do not have a lower corrosion resistance.

\section{Acknowledgement}

The authors wish to thank CAPES (Brazil) and DAAD (Germany) for financial support.

\section{References}

1. Kurze, P.; Banerjee, D. Giesserei-Praxis, v. 11-12, p. 211-217, 1996.

2. Olbertz, B.; Giesserei-Praxis, v. 19, p. 304-307, 1989.

3. Metals Handbook, v.2, American Society for Metals, Metals Park, Ohio, $8^{\text {th }}$ Ed., p. 648-660, 1979.
4. Groshart, E. Metal Finishing, p. 59-61, 1997.

5. Barton, T.F.; Johnson, C.B. Plating and Surface Finishing, v. 82, p. 138-141, 1995.

6. Yerokhin, A.L.; Nie, X.; Leyland, A.; Matthews, A.; Dowey, S.J. Surface and Coatings Technology, v. 122, p. 73-93, 1999.

7. Kurze, P.; Banerjee, D. Trattamenti \& Finiture, n. 3-4, p. 144147, 1997.

8. Brown, R.E.; Light Metal Age, v. 51, p. 14-17, 1993.

9. Voevodin, A.A.; Yerokhin, A.L.; Lyubimov, V.V.; Donley, M.S.; Zabinski, J.S. Surface and Coatings Technology, v. 86-87, p. 516$521,1996$.

10. Xue. W.; Deng, Z.; Lai, Y.; Chen, R. J. Am. Ceramic Society, v. 81, p. $1385,1998$.

11. Nie, X.; Leyland, A.; Song, H.W.; Yerokhin, A.L.; Donley, S.J.; Matthews. A. Surface and Coatings Technology, v. 116-119, p. 1055-1060, 1999.

12. Peixoto Barbosa, D.; Knörnschild, G. XII. SIBEE - Simpósio Brasileiro de Eletroquímica e Eletroanalítica, Gramado, Rio Grande do Sul, p. 361-363, April 2001.

13. Cohen, S.M. Corrosion, v. 51, p. 71, 1995.

14. Atz, N.R.; Knörnschild, G.; Dick, L.F.P.; Stratmann, M. $8^{\text {th }}$ Int. Symp. on Passivity of Metals and Semiconductors, Jasper, Canada, May 9-14, 1999. 